\title{
Apparent thermal conductivity of photoluminescent C-dot nanofluid
}

\author{
Ashkan Vatani ${ }^{\mathrm{a}, \mathrm{c}^{*}}$, Peter L. Woodfield ${ }^{\mathrm{a}}$, Tak H. Kim ${ }^{\mathrm{a}, \mathrm{d}}$, Charles Lemckert ${ }^{\mathrm{b}}$, Qin Li ${ }^{\mathrm{a}, \mathrm{e}}$, \\ Dzung Dao ${ }^{\mathrm{a}, \mathrm{e}}$
}

${ }^{\text {a}}$ School of Engineering and Built Environment, Griffith University, QLD, Australia

${ }^{b}$ Faculty of Arts and Design, University of Canberra, ACT, Australia

'Department of Mechanical and Aerospace Engineering, Monash University, VIC, Australia

${ }^{\mathrm{d} S c h o o l}$ of Environment and Science, Griffith University, QLD, Australia e Queensland Micro- and Nanotechnology Centre, Griffith University, QLD,

Australia

*Corresponding author

ashkan.vatani@griffithuni.edu.au

\begin{abstract}
Carbon nanodots (C-dots) are nanometer-sized particles of amorphous carbon that form highly stable water-based suspension if given the right surface treatment. Their size, stability and unique photoluminescent properties make them attractive candidates for tracer materials for use in heat transfer experiments. Here we measure the effective thermal conductivity of water containing $1.5 \mathrm{~g} / \mathrm{L}(0.077 \%$ volume fraction $)$ of fluorescent green carbon nanodots. In conflict with empirical predictions from nanofluid literature but consistent with predictions from classical theories applied to nanofluid thermal conductivity enhancement, the results show no measurable difference between the thermal conductivity of the colloid and deionized water. This finding adds confirmation to the value of photoluminescent carbon nanodots for use as a water tracer in bench-top heat transfer experiments.
\end{abstract}

Key words: Carbon nanodots; Fluorescent tracer; Photoluminescent nanofluid; Thermal conductivity

\section{Introduction}


Photoluminescence is a fascinating material property of fluorescent tracers where exposure to ultra-violet light causes a release of light in the visible spectrum. This phenomenon has formed the basis for the development of powerful techniques for tracking, detection and flow visualization [1-3]. Fluorescent tracers are particularly valuable for heterogeneous and biological fluids [4] in that the tracer's unique response to the UV excitation generally makes it easily distinguishable from other substances.

Fluorescent dyes are the most commonly-used photoluminescent tracer materials with a relatively smaller number of studies utilizing photoluminescent particles. For nanofluids (colloidal suspensions of nanometer-sized particles in a liquid), injection of rhodamine and other fluorescent dyes has been an effective tool for investigating mass transfer and self-diffusion of water in the presence of nanoparticles [5-10]. Micrometersized particles have been used with success as tracers in heat transfer experiments (e.g. Ref. [11]). While fluorescent chemical dyes may be in common use, considerably less attention has been given to fluorescent nanometer-sized solid particles for tracer applications in the field of heat transfer. Carbon dots appear to be an ideal candidate for a nanoparticle tracer with some success already reported for water flow in porous media [1].

Carbon dots have unique, tunable photoluminescent properties [12] and thus great potential for use as a tracer in heat transfer research. Since the discovery of carbon dots [13] carbon dots have received intense research interests owing to their unique optical properties, biocompatibility and ease in synthesis [14]. Zhu et al [15] in a comprehensive review demonstrated the four mechanisms of the photoluminescence for the three types of fluorescent carbon dots, namely the quantum confinement effect (or conjugated $\pi$-domains determined by carbon core), surface state determined by hybridization of the carbon backbone and the connected chemical groups, the molecule state determined by the solely fluorescent molecules connected on the surface or inner of the CDs, and the crosslink enhanced emission (CEE) effect. Li and Dong [16] highlighted a series of photoluminescence mechanisms that provide insight into synthesis techniques to enhance photoluminescence properties of carbon dots. 
Water containing carbon dots can be classified as a nanofluid since the particles in suspension are significantly smaller than $100 \mathrm{~nm}$ [17] which adds an interesting complication for development of a passive nano-particle tracer for heat transfer experiments. Nanofluids are famous for significantly enhanced effective thermal conductivity above that of water even for low particle concentrations [18]. Therefore, it is important to investigate the extent to which the nanoparticle tracer's presence may influence the results of a heat transfer experiment. The majority of studies related to the effective thermal conductivity of nanofluids have focused on situations where enhancement to thermal properties is the desired effect. In contrast, for tracers, the desired behavior is that the probe has negligible effect on the properties of the base fluid.

The importance of various mechanisms for explaining the observed enhancement to thermal conductivity of nanofluids is still under some debate $[19,20]$. The enhancement due to the presence of the nanoparticles is firstly due to the larger thermal conductivity of the particle material relative to the base fluid resulting in an increase in the 'static' contribution to the apparent thermal conductivity of the suspension [21]. Several theories are connected to the Brownian motion of the particles colliding with fluid molecules and consequently an augmented 'dynamic' contribution (i.e. related to particle motion) to the effective thermal conductivity [21,22]. This contribution to the thermal conductivity has been found to be directly proportional to temperature [22], since the Brownian motion of the particles increases with rising temperature. It is also reported that the dynamic contribution to thermal conductivity enhancement should be inversely proportional to the particles' size [20-23]. Smaller particles, due to their lighter weights, gain larger Brownian velocities than larger particles [23]. Therefore nanofluids with smaller particle size are expected to have larger enhanced thermal conductivities. Based on these two considerations it is meaningful to attempt to measure the effective thermal conductivity of a photoluminescent $\mathrm{C}$-dot nanofluid as a function of temperature.

While carbon nanotube-based nanofluids have been given great consideration [24], measurements of effective thermal conductivity of amorphous carbon/water nanofluids (such as carbon-dot colloids) appear to be absent from the literature. Compared with metallic or ceramic particles, graphene flakes or carbon nanotubes (which may have 
thermal conductivities 100 s or 1000 s of times that of water), amorphous carbon has a relatively low thermal conductivity $\left(\sim 1.6 \mathrm{~W} \cdot \mathrm{m}^{-1} \cdot \mathrm{K}^{-1}\right)[25]$ being only little higher than that of water $\left(\sim 0.6 \mathrm{~W} \cdot \mathrm{m}^{-1} \cdot \mathrm{K}^{-1}\right)[26]$. While this is promising for the tracer application, studies with nanometer-thin films of amorphous carbon show strong size dependence of the thermal conductivity on the thickness of the film [27]. For prediction of the effective thermal conductivity of the carbon nanodot nanofluid in this study we have assumed that the solid material has a thermal conductivity of $1.6 \mathrm{~W} \cdot \mathrm{m}^{-1} \cdot \mathrm{K}^{-1}$.

\section{Measurement methodology}

The transient short hot-wire method [28-31] was used to measure the thermal conductivity of the carbon-dot nanofluid. This technique is a variant of the standard transient hot wire method $[32,33]$ with the key difference that only a single wire is used and end effects are accounted for by numerical solution of the 2D axisymmetric transient heat conduction equation:

$$
\rho c \frac{\partial T}{\partial t}=\frac{1}{r} \frac{\partial}{\partial r}\left(r \lambda \frac{\partial T}{\partial r}\right)+\frac{\partial}{\partial z}\left(\lambda \frac{\partial T}{\partial z}\right)+Q
$$

where $\lambda$ is the thermal conductivity, $\rho$ the density, $c$ specific heat and $Q$ the Joule heating per unit volume in the wire (zero at radial positions greater than the wire radius). The cell walls are assumed to act as isothermal boundaries for the problem. The initial condition corresponds to the same isothermal temperature. Convection heat transfer effects can be neglected provided the measurement time is short enough [33, 34].

A new measurement cell was constructed consisting of a circular channel $50 \mathrm{~mm}$ in length and $5 \mathrm{~mm}$ in diameter, drilled in an acrylic cube. A $50 \mu \mathrm{m}$ diameter platinum microwire passes through the channel and is soldered at the two ends to micrometer thin copper tapes. Using a programmable power supply, a constant electrical current is applied to the platinum wire and the transient voltage is measured using a multimeter and recorded via a LabVIEW ${ }^{\mathrm{TM}}$ program. A detailed overview of the measurement set up is given in [29]. Voltages are converted to resistances and the temperature of the wire is calculated with the following equation:

$$
T=\left(\frac{R}{R_{0}}-1\right) / \sigma
$$


where $R_{0}$ is the resistance of the wire at $0{ }^{\circ} \mathrm{C}$ and $\sigma$ is the temperature coefficient of resistance. Then the thermal conductivity is then determined from a least-squares fit of the measurement data to the transient solution of the $2 \mathrm{D}$ axisymmetric heat conduction equation (Eq. (1)) [30, 31].

Figure 1 shows an example of the variation of the average wire temperature rise with logarithm of time during heating of the wire. The fit from the numerical simulation used to determine the thermal conductivity is shown as a solid line. When the measured temperature rise is plotted against the logarithm of time, typically a straight line appears. While the bath temperature in this case was $19.5^{\circ} \mathrm{C}$, the reference temperature for thermal conductivity measurement is $25.4^{\circ} \mathrm{C}$, which corresponds to the average of the highest and lowest measurement point temperature in Fig. 1 as recommended by Healy et al [32]. For the C-dot nanofluid case shown in Fig. 1, the fit from the numerical simulation corresponds to a thermal conductivity of $0.605 \mathrm{~W} \cdot \mathrm{m}^{-1} \cdot \mathrm{K}^{-1}$.

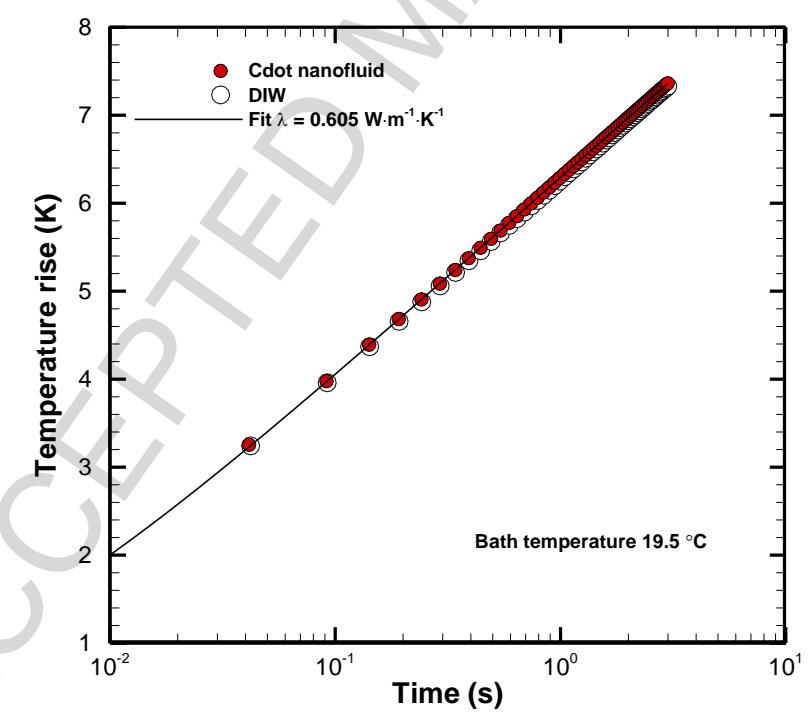

Figure 1 Variation of heated wire temperature with logarithm of time

To investigate the relative importance of various parameters on measured outputs, an uncertainty analysis was performed as listed in Table 1 . All calculations for propagation and combination were done based on standard uncertainties. The uncertainty in the length of the cell was $\pm 1 \mathrm{~mm}$ (corresponding to $2 \%$ ). The absolute uncertainty in the initial bath temperature was $0.5^{\circ} \mathrm{C}$ with stability of better than $0.05^{\circ} \mathrm{C}$ for the duration 
of an experiment. The uncertainty in the calibrated temperature coefficient of resistance (TCR) of the wire was $0.6 \%$ based on the precision of the bath temperature. The uncertainties in the supplied DC current and measured voltage were $0.05 \%$ and $0.001 \%$, respectively (according to device manual) leading to the values shown in Table 1 for a $1 \mathrm{~A}$ range on the current source and $2 \mathrm{~V}$ range on the multimeter. The overall uncertainty of measurement is calculated to be $2.3 \%$.

Table 1 Uncertainty Analysis ( $2 \sigma$ standard uncertainties)

\begin{tabular}{ccc}
\hline Variable & Uncertainty & $\begin{array}{c}\text { Effect on thermal } \\
\text { conductivity measurement } \\
(\%)\end{array}$ \\
\hline $\begin{array}{c}\text { Voltage } \\
\text { measurement }\end{array}$ & $20 \mu \mathrm{V}$ & 0.00 \\
\hline $\begin{array}{c}\text { Current } \\
\text { measurement }\end{array}$ & $0.0005 \mathrm{~A}$ & 0.04 \\
\hline TCR & $0.6 \%$ & 0.6 \\
\hline $\begin{array}{c}\text { Wire length } \\
\text { Reference } \\
\text { fluid (DIW) } \\
\text { thermal }\end{array}$ & $2 \%$ & 1 \\
\hline conductivity & $1 \%$ & $2.3 \%$ \\
\hline \multicolumn{1}{c}{ Combined uncertainty } \\
\hline
\end{tabular}

\section{Carbon-dot sample preparation}

The carbon nanodot sample was prepared using procedures reported previously [35]. The chemicals for the sample preparation were purchased from Chem-Supply Pty Ltd, Australia and were used as received. Dialysis membranes were from Spectrum Laboratories Inc. Synthesis of the samples was carried out in a $30 \mathrm{~mL}$ PTFE-lined autoclave. Masses of $0.5 \mathrm{~g}$ of urea and $0.16 \mathrm{~g}$ of citric acid were mixed (10:1 molar ratio) in either glycerol or water $(10 \mathrm{~mL})$ and placed in the autoclave. The autoclave was sealed and maintained at $180{ }^{\circ} \mathrm{C}$ for 24 hours and then was cooled to room temperature. 
Dialysis was performed twice at different molecular weight cut-offs in order to obtain pure and mono-dispersed C-dot samples. Prior to dialysis, all the samples were filtered through $0.22 \mu \mathrm{m}$ syringe filters to remove large aggregates. The filtrate was subsequently placed in a $3.5 \mathrm{kDa}$ membrane bag (the volume of each dialysis bag was prepared at $80 \mathrm{~mL})$ and dialyzed against a large amount of water $(20 \mathrm{~mL}$ of sample solution/6 L of water for 36 hours, $500 \mathrm{~mL}$ of water was added every 2 hours and left for an additional 12 hours). The sample out of the $3.5 \mathrm{kDa}$ bag was condensed in a rotary evaporator and the condensed sample was placed in a $1 \mathrm{kDa}$ membrane bag for further dialysis. After the second dialysis, the sample in the $1 \mathrm{kDa}$ membrane bag was collected and used for the experiments.

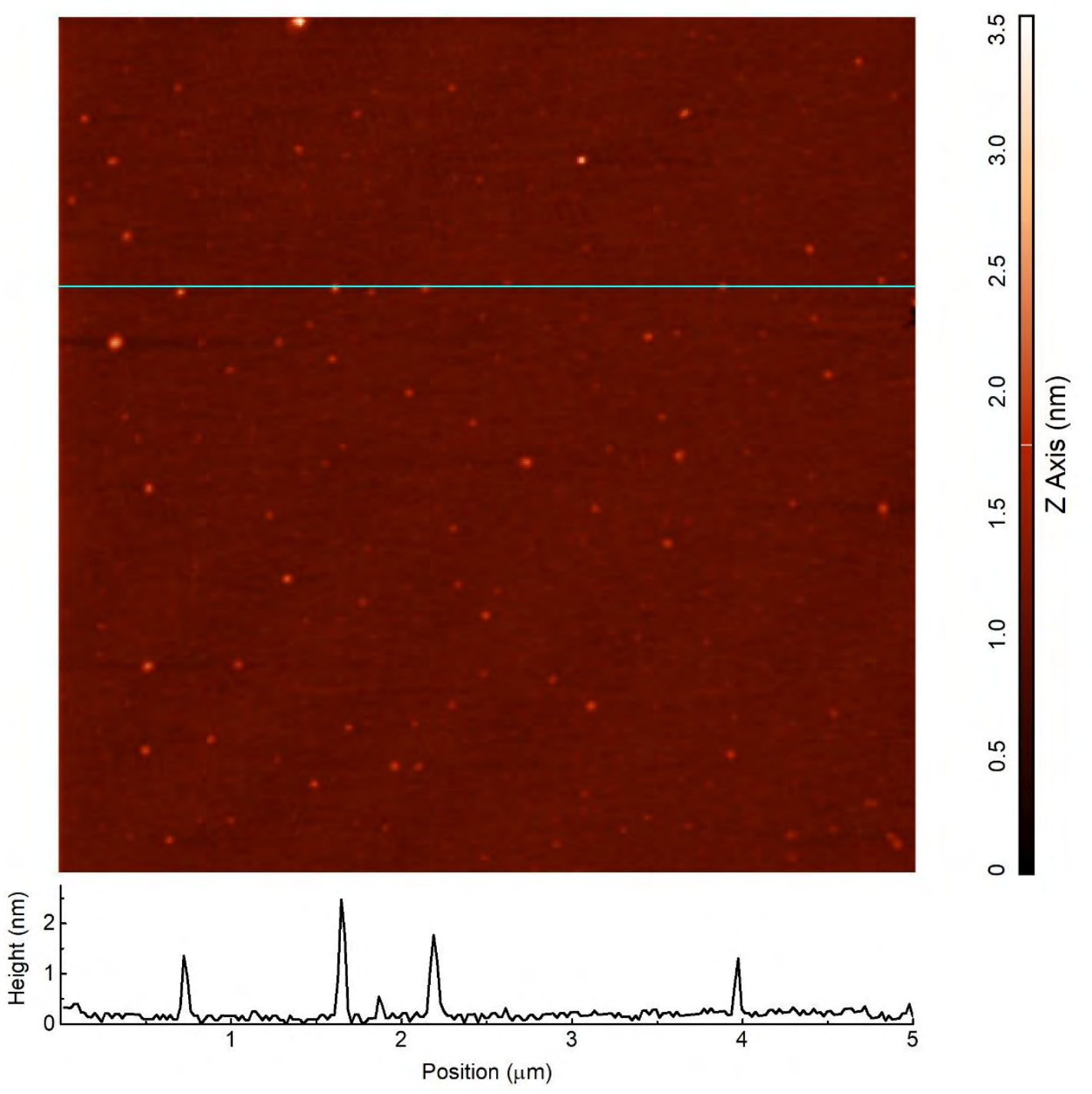


Figure 2 Atomic force microscopic image of the carbon dots. A height profile of the cross-section (cyan line) is provided to present the size of the sample on the crosssection.

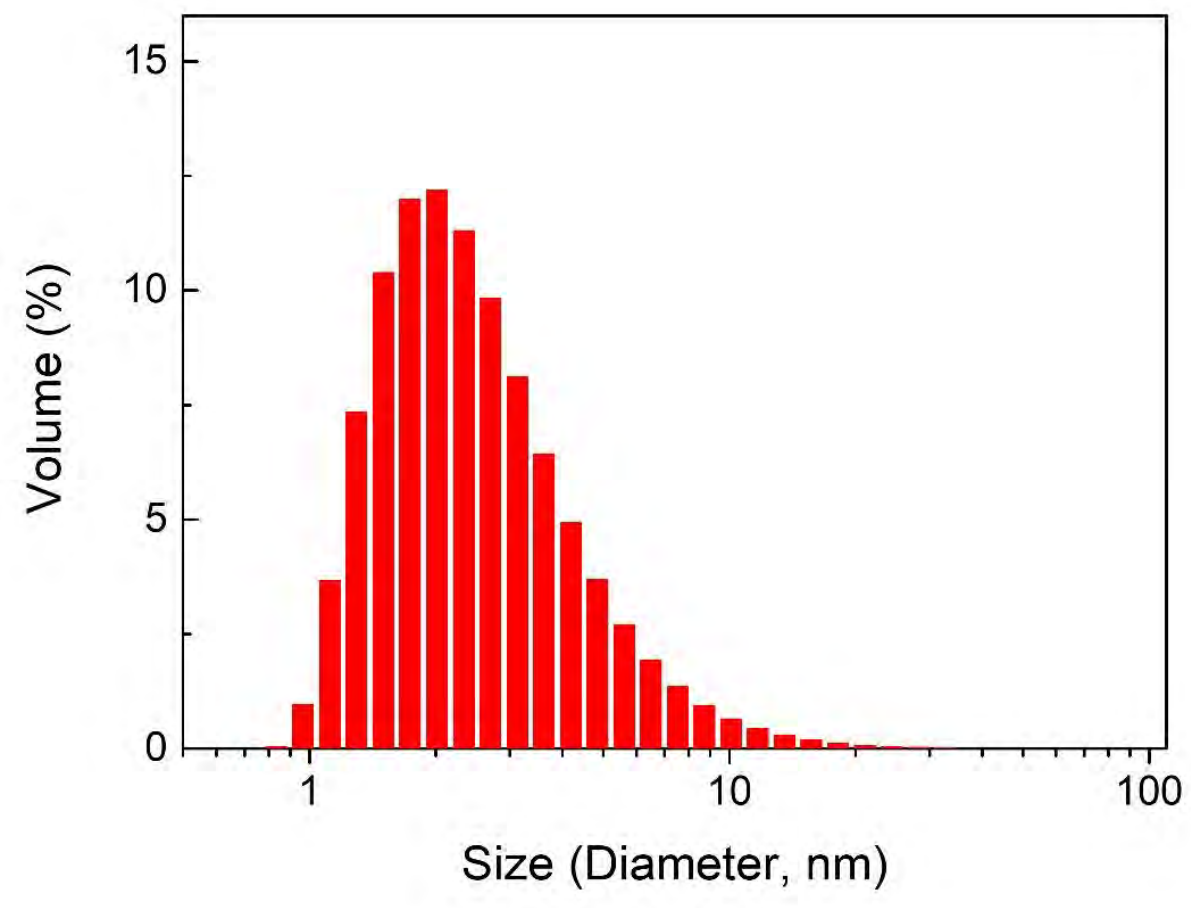

Figure 3 Particle size distribution of the Carbon dots measured by DLS.

The particle sizes were characterized by atomic force microscopy (AFM) and dynamic light scattering (DLS). As illustrated in Figure 2, the majority of particles were measured between 1 and $4 \mathrm{~nm}$ by AFM. The size distribution from the DLS measurement was in agreement (Fig. 3), showing a log-normal distribution ranging from 1 to $10 \mathrm{~nm}$ and peaking at $2 \mathrm{~nm}$. The relative increase in particle distribution in the DLS can be attributable to the hydration layer from the peripheral functionality. For the purpose of testing empirical equations for predicting thermal conductivity, the nanoparticle sample diameter was taken to be $2 \mathrm{~nm}$ corresponding to the peak in the size distribution (Fig. 3). 


\section{Experimental results}

The thermal conductivity of the colloid of $2 \mathrm{~nm}$ diameter carbon nanodots in water with $0.077 \%$ particle volume fraction was measured at four temperatures in the range from $15^{\circ} \mathrm{C}$ to $45^{\circ} \mathrm{C}$. It is observed that the temperature rise of the wire is almost identical in both nanofluid and deionized water as can be seen, for example, in Fig. 1 which also shows the temperature rise for deionized water (DIW).

Figure 4 shows the measured thermal conductivity of the nanofluid sample and deionized water at different temperatures. This figure also compares the measured data with the standard IAPWS correlation for water using the National Institute of Standard and Technology (NIST) database [36] and predicted results for nanofluid thermal conductivity enhancement [37-39]. Maxwell's relation for effective conductivity of composite solids [37] sometimes under-predicts the enhancement while the empirical correlations of Corcione [38] and Chon et al [39], have been shown to produce acceptable agreement with available experimental data on nanofluid effective conductivity in the literature [19]. It is observed in Fig. 4 that measured data of deionized water are in very good agreement with standard values of NIST. The measured data for nanofluid present a non-significant enhancement over deionized water.

It should be noted that the hotwire probe was calibrated using water thermal conductivity at $35.5{ }^{\circ} \mathrm{C}$ (to account for small differences between the ideal model and experiment [28]) so good agreement with the NIST database is expected for this particular temperature. Figure 4 also shows that the empirical correlation of Corcione predicts a significant enhancement in the thermal conductivity of the nanofluid over deionized water due to very small particles size and this enhancement increases with increasing temperature, while Maxwell's relation and the correlation proposed by Chon et al predict no such enhancement. Considering the uncertainty in the measurement $( \pm$ $2 \%$ with a coverage factor of 2 standard deviations for this technique [28]), the present results are more consistent with the negligible change $(<0.4 \%)$ to thermal conductivity predicted using Maxwell and Chon's correlations. Thus carbon-dot concentrations smaller than $0.08 \%$ volume-fraction are not expected to interfere with the thermal conductivity of the base fluid if the dots are used as water tracers. 


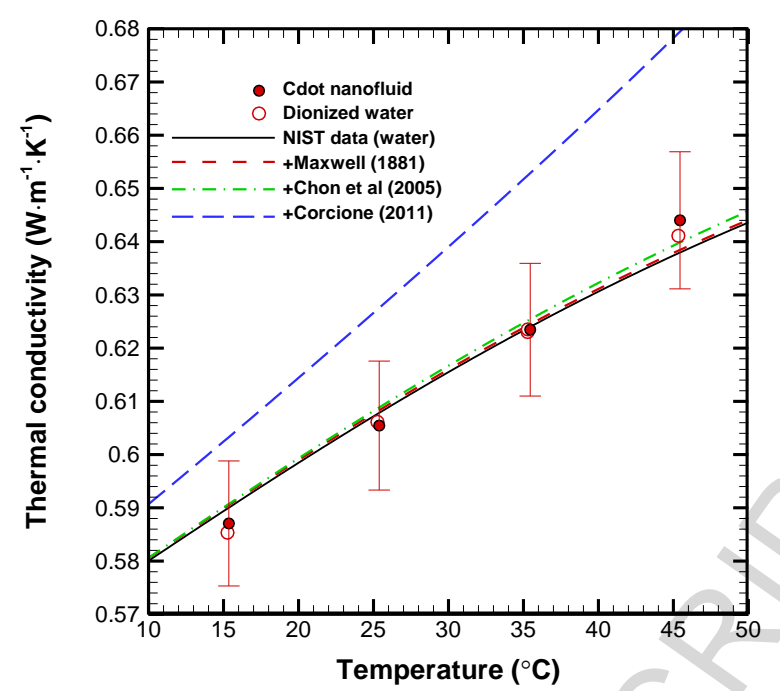

Figure 4 Thermal conductivity of C-dot nanofluid against temperature $(0.077 \%$ particle volume fraction)

\section{Detection limits for the tracer}

To confirm the validity of the key conclusion of this study, it is of value to show that the tracer concentration does not need to be greater than $0.077 \%$ volume fraction (c.f. Fig. 4, i.e. the case measured) for use as a tracer. To confirm this, we considered a simple setup where a sample with concentrations ranging from 0 to $150 \mu \mathrm{L} / \mathrm{mL}$ (volume fraction of carbon dots $0-0.012 \%$ ) was excited using a blue LED via a fibre optic cable at $90^{\circ}$ to the detector in a darkened room. Detection was done using a $\mathrm{UV} \rightarrow$ visible spectrometer (LASTEK-001 4399). Fig. 5 shows the spectral distribution of emitted light in arbitrary units. The peaks of the distributions appear for wavelengths around $535 \mathrm{~nm}$ which corresponds to the visible colour - light green. 

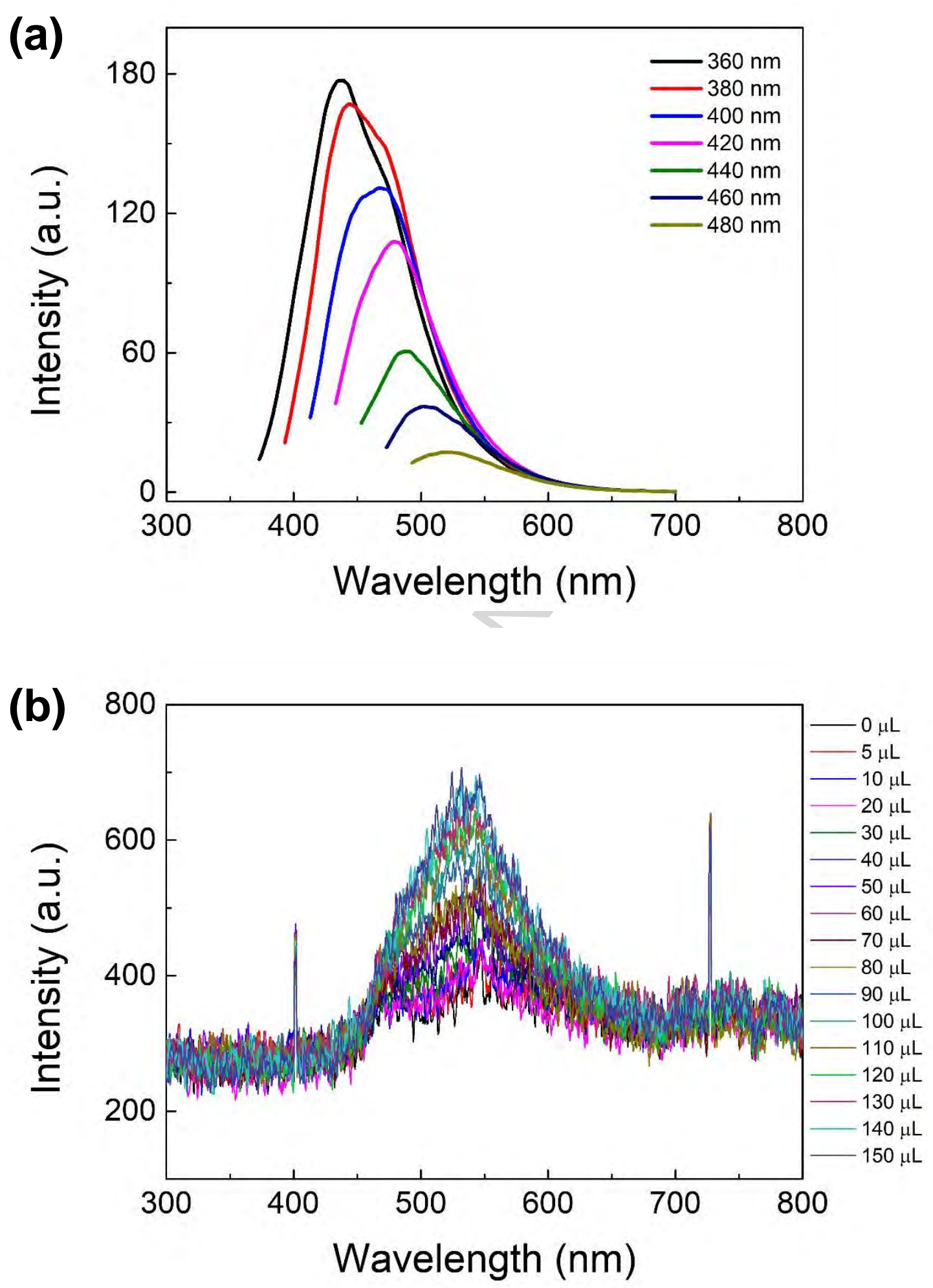

Fig. 5 (a) Photoluminescence emission measured at different excitation wavelength in a fluorescence spectrometer and (b) emission intensity for different dilutions of C-dot 
nanofluid under $470 \mathrm{~nm}$ excitation. Concentrations are listed as $\mu \mathrm{L}$ of concentrated Cdot nanofluid per $\mathrm{mL}$ of final mixture prepared at $1.5 \mathrm{~g}$ of $\mathrm{C}$-dots per litre of mixture.

Plotting the peak intensity against the concentration gives the result shown in Fig. 6 . There is a clear linear trend between concentration and intensity which is good for interpreting measured intensities in deionized water as concentrations of C-dots. The minimum detectable limit with the equipment used was estimated at $0.9 \mu \mathrm{L}$ of concentrated nanofluid per $\mathrm{mL}$ of water $(\mathrm{C}$-dot volume fraction of $0.7 \mathrm{ppm})$. The main limitations are the background light from the room ( 380. a.u. in Fig. 6$)$ and noise in the data. Thus it is confirmed that the tracer can be used for concentrations significantly smaller than the concentration used in the thermal conductivity test (Fig. 4).

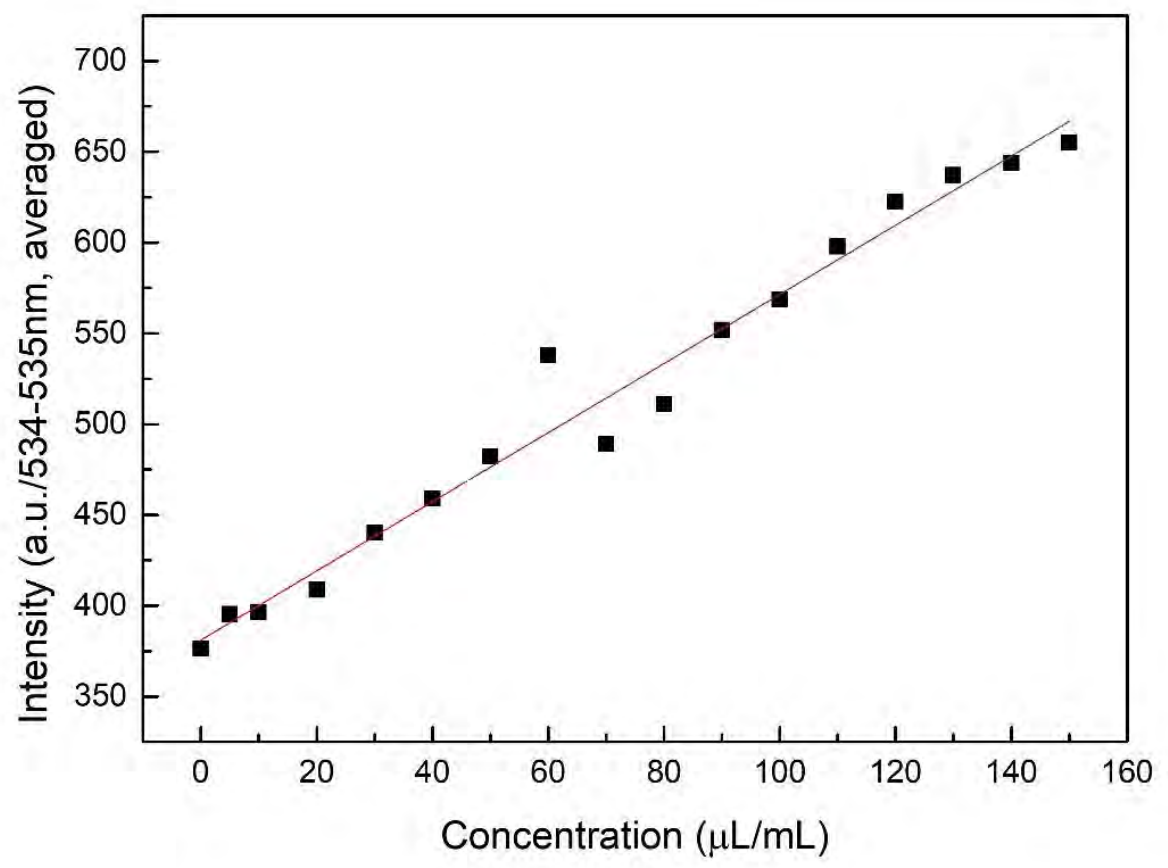

Fig. 6 Measurement of peak intensity obtained from Fig. 5 (b) under $470 \mathrm{~nm}$ excitation

\section{Conclusion}

Carbon nanodots have promising characteristics for use as tracer materials in heat transfer experiments. For such applications, any change in fluid properties as a result of addition of Cdots is undesired. Therefore, the thermal conductivity of a dilute $\mathrm{Cdot} /$ water nanofluid was measured. It was confirmed that for concentrations less than 
$0.08 \%$ the thermal conductivity of a carbon nanodot nanofluid is indistinguishable from that of deionized water. It was also shown that to be applicable for photoluminescence applications, the volume fraction of Cdots does not need to be more than $0.08 \%$. Future studies should consider other properties of the Cdot nanofluid such as toxicity of the fluid and practical demonstrations with Cdots used as a thermofluid tracer.

\section{Acknowledgements}

Support of GSE strategic seed funding scheme is acknowledged gratefully.

\section{References}

[1] S. Subramanian, Y. Li, L. Cathles, Water Resources Research 49 (2013) 29.

[2] W. Wang, T. Kim, Z. Yan, G. Zhu, I. Cole, N.-T. Nguyen, Q. Li, Journal of colloid and interface science 437 (2015) 28.

[3] J. Veilleux, S. Coulombe, International Journal of Heat and Mass Transfer 53 (2010) 5321.

[4] Q. Li, T.Y. Ohulchanskyy, R. Liu, K. Koynov, D. Wu, A. Best, R. Kumar, A. Bonoiu, P.N. Prasad, The Journal of Physical Chemistry C 114 (2010) 12062. [5] S.-S. Ashrafmansouri, M.N. Esfahany, G. Azimi, N. Etesami, International Journal of Thermal Sciences 86 (2014) 166.

[6] S. Krishnamurthy, P. Bhattacharya, P. Phelan, R. Prasher, Nano letters 6 (2006) 419.

[7] X. Fang, Y. Xuan, Q. Li, Applied Physics Letters 95 (2009) 203108.

[8] C. Pang, J.W. Lee, Y.T. Kang, International Journal of Thermal Sciences 87 (2015) 49.

[9] S.-S. Ashrafmansouri, M.N. Esfahany, International Journal of Thermal Sciences 82 (2014) 84.

[10] V. Subba-Rao, P.M. Hoffmann, A. Mukhopadhyay, Journal of Nanoparticle Research 13 (2011) 6313.

[11] B. Chen, F. Mikami, N. Nishikawa, International journal of heat and mass transfer 48 (2005) 2933.

[12] R. Liu, D. Wu, S. Liu, K. Koynov, W. Knoll, Q. Li, Angewandte Chemie International Edition 48 (2009) 4598.

[13] Y.-P. Sun, B. Zhou, Y. Lin, W. Wang, K.S. Fernando, P. Pathak, M.J. Meziani, B.A. Harruff, X. Wang, H. Wang, Journal of the American Chemical Society 128 (2006) 7756.

[14] B. Yao, H. Huang, Y. Liu, Z. Kang, Trends in Chemistry (2019).

[15] S. Zhu, Y. Song, X. Zhao, J. Shao, J. Zhang, B. Yang, Nano research 8 (2015) 355.

[16] L. Li, T. Dong, Journal of Materials Chemistry C 6 (2018) 7944.

[17] D. Wen, G. Lin, S. Vafaei, K. Zhang, Particuology 7 (2009) 141.

[18] S.U. Choi, J.A. Eastman, Argonne National Lab., IL (United States), 1995.

[19] A. Vatani, P.L. Woodfield, D.V. Dao, Journal of Molecular Liquids 211 (2015) 712.

[20] M.M. Tawfik, Renewable and Sustainable Energy Reviews 75 (2017) 1239. 
[21] X.-Q. Wang, A.S. Mujumdar, International journal of thermal sciences 46 (2007) 1.

[22] S.P. Jang, S.U. Choi, Applied physics letters 84 (2004) 4316.

[23] M. Chopkar, S. Sudarshan, P. Das, I. Manna, Metallurgical and Materials Transactions A 39 (2008) 1535.

[24] S.S. Murshed, C.N. De Castro, Renewable and Sustainable Energy Reviews 37 (2014) 155.

[25] C.Y. Ho, R.W. Powell, P.E. Liley, NATIONAL STANDARD REFERENCE DATA SYSTEM, 1974.

[26] J. Kestin, J. Sengers, B. Kamgar-Parsi, J.L. Sengers, Journal of Physical and Chemical Reference Data 13 (1984) 175.

[27] A. Balandin, M. Shamsa, W. Liu, C. Casiraghi, A. Ferrari, Applied Physics Letters 93 (2008) 043115.

[28] M. Fujii, X. Zhang, N. Imaishi, S. Fujiwara, T. Sakamoto, International journal of thermophysics 18 (1997) 327.

[29] A. Vatani, P.L. Woodfield, D.V. Dao, Microsystem Technologies 22 (2016) 2463.

[30] P. Woodfield, J. Fukai, M. Fujii, Y. Takata, International Journal of Thermophysics 30 (2009) 796.

[31] P. Woodfield, J. Fukai, M. Fujii, Y. Takata, K. Shinzato, International Journal of Thermophysics 29 (2008) 1299.

[32] J. Healy, J. De Groot, J. Kestin, Physica B+ c 82 (1976) 392.

[33] X. Zhang, S. Fujiwara, Z. Qi, M. Fujii, JASMA: Journal of the Japan Society of Microgravity Application 16 (1999) 129.

[34] A. Vatani, P.L. Woodfield, N.-T. Nguyen, D.V. Dao, Journal of Magnetism and Magnetic materials 456 (2018) 300.

[35] T.H. Kim, J.P. Sirdaarta, Q. Zhang, E. Eftekhari, J.S. John, D. Kennedy, I.E. Cock, Q. Li, Nano Research 11 (2018) 2204.

[36] M.W. Chase Jr, N.-J.T. Tables, J. Phys. Chem. Ref. Data, Monograph 9 (1998) 1. [37] J.C. Maxwell, A treatise on electricity and magnetism. Clarendon press, 1881. [38] M. Corcione, Energy Conversion and Management 52 (2011) 789.

[39] C.H. Chon, K.D. Kihm, S.P. Lee, S.U. Choi, Applied Physics Letters 87 (2005) 153107. 


\section{Highlights}

- Water/C-dot nanofluid sample with $0.077 \%$ volume fraction was prepared.

- Effective thermal conductivity of water containing $1.5 \mathrm{~g} / \mathrm{L}$ ) of fluorescent green carbon nanodots is measured.

- The measured thermal conductivity of the nanofluid is found to be in contrast with the predictions of classical theories.

- No measurable enhancement in the effective thermal conductivity of the water is observed by adding C-dot particles. 